\title{
Diminishing Manufacturing Sources and Material Sources Impacting the Microwave Tube Industry
}

\author{
Mitsdarffer, K. Bryan \\ Naval Surface Warfare Center, Crane \\ 300 Highway 361, Code GXR Bldg. 3168 \\ Crane, IN, 47522-5001
}

\author{
Connor, Derrick \& Effgen, Michael P. \\ Semicon Associates \\ 695 Laco Drive \\ Lexington, Ky 40510
}

\begin{abstract}
Over the years, issues with the supply of Beryllium, Beryllium Oxide, Thoriated-Tungsten wire, Rare-earth metals for magnets (Samarium-Cobalt), Tungsten, and recently Tungsten-Rhenium wire have put the supply of Microwave Tubes at risk. These Diminishing Manufacturing Source and Material Source (DMSMS) issues continue to be addressed by the Microwave Tube industry and with the help of US government programs like the Defense Production Act (Title III), Small Business Innovation Research (SBIR/STTR), ManTech, Defense Logistics Agency programs (S\&T, Industrial Base Innovation Funding, Warstopper, Working-Capital-Fund, and Strategic Materials) and Department of Defense (DoD) program investments.
\end{abstract}

Keywords: DMS; tungsten; rhenium; wire; rare earth magnets.

Introduction: Microwave tubes are still a critical technology to DoD weapons systems (70 \% of DoD weapon-systems with active emitters) even though the Solid-state technology continues to be the technology of choice in new systems. This transition of technology in DoD weapon systems has been projected for decades and will take several more decades to complete leaving DoD with small, yet critical industrial base to support many DoD weapons system needs. DoD procurement represents $\sim 80 \%$ of the industrial base US sales.

Microwave tubes are high-power, high-vacuum devices and use many rare-earth metals and specialized materials and parts. As with many other industries, the changing international market for these materials has caused price (variation and increase), lost of US sources and in some cases requires new material solutions. Low volume usage, the need for specialized processing and consistency in material properties add to the difficulty in maintaining sources of these materials.

Over the years, issues with the supply of Beryllium, Beryllium Oxide, Thoriated-Tungsten wire, Rare-earth metals for magnets (Samarium-Cobalt), Tungsten, and recently Tungsten-Rhenium wire have put the supply of Microwave tubes at risk.

These DMSMS issues continue to be addressed by the Microwave tube industry and with the help of US government programs like the Defense Production Act
(Title III), Small Business Innovation Research (SBIR/STTR), ManTech, Defense Logistics Agency programs (S\&T, IBIF, Warstopper, Working-Capital-Fund, and Strategic Materials) and DoD program investments.

\section{Current Issue - Cathode Manufacturing and} Tungsten-Rhenium wire: Tungsten-Rhenium wire is used extensively in the manufacture of heaters for thermionic cathodes used in most microwave tubes. Economic reality of today's market is that the old costdrivers of labor, yield and scrap have taken a back seat to the cost of materials and the global economy realities are causing lost of US industrial sources. Where materials used to see only predicable inflationary increase year to year, today see increases happening day to day. A good portion of this volatility can be attributed to economic globalization and the rapid increase in industrialization in Asia and developing nations. This increase has and is having a dramatic effect on the demand side of supply. The demand curves are creating the volatility in the materials markets, and are having a particularly dramatic effect on the materials used in the manufacture of vacuum electron devices.

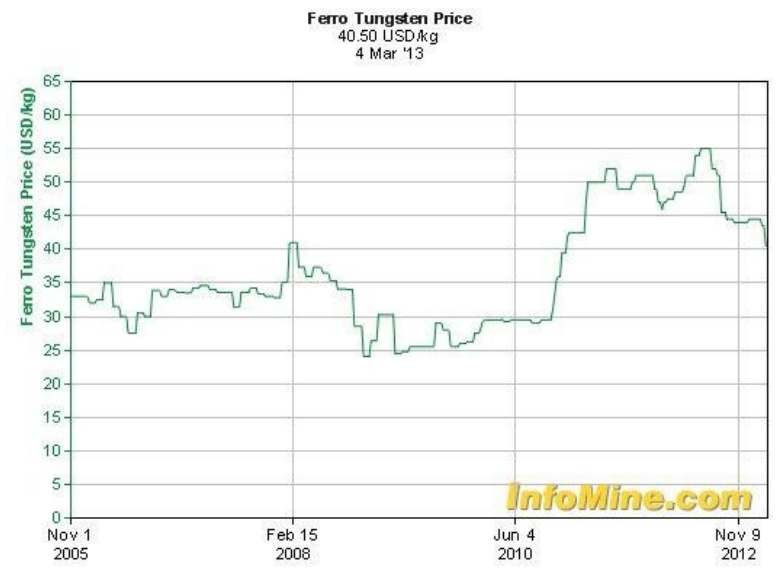

Figure 1: Ferro-Tungsten pricing November 2005 to March 2013

Figure 1 details how Tungsten supply and pricing were relatively stable from 2005 to 2010 even while demand 
continued to rise. Continued growth and market pressures caused an increase in pricing late 2010 and will likely increase in 2013 as China continues to decrease the export of raw materials.

Rhenium is easily the rarest of all the refractory materials, 120 tons of copper ore typically yields only 1 gram of this material. It, like Molybdenum, has seen significant spikes in demand for industrialization and aerospace uses and its demand has affected pricing.

Rhenium's main use (70\%) is for mixing with hightemperature super-alloys used in jet engine parts. The microwave tube industry uses Rhenium mixed with Tungsten to form wire which is wound into a variety of configurations for heater applications and flattened into ribbon for $r f$ helices. The total usage of tungsten rhenium wire by the microwave tube industry is very small as compared to pure Tungsten or Molybdenum based wire, but it is critical to the operation of these devices.

Microwave Tube Industry DMS Working Group: After completion of the 2012 International Vacuum Electronic Conference a working group comprised of members from the majority of the microwave tube vendors and sub-vendors impacted by the Tungsten-Rhenium wire started meeting in the attempt to cooperatively solve the loss of the tungsten-rhenium wire source. Personnel from the following companies are included within the group: $\mathrm{H}$. Cross Company, Union City Filament, Semicon Associates, Spectra-mat, Communications and Power Industries, e2v, L-3 Communications, Northrop Grumman, Photonis USA, Teledyne, TMD, Thales and NSWC Crane.
The group has worked collectively to perform market research to find replacement US and foreign sources for a tungsten-rhenium wire replacement while generating an improved specification for future wire sources. The group is also working to finalize a uniform qualification plan to implement for future additional sources at the electron gun and helices sub-assembly level in the attempt to minimize cost and expedite qualification of a new wire source prior to the end of 2013.

\section{Conclusion}

As the global economies continue to grow; further pressures on supply and price for the materials used in the manufactures of Microwave Tubes will not abate. The intent this abstract is not to offer solution to pending price increases nor to address the potential for significant material shortages, but to inform the industry on progress to resolve the existing DMS issue involving TungstenRhenium wire and to start a dialog within the industry on how to deal with these issues and the issues to come.

\section{Acknowledgements}

The authors wish to thank the people and companies currently engaged in the microwave tube industry working group attempting to resolve the issue of losing the microwave tube industries sole qualified source for tungsten rhenium wire.

\section{References}

1. www.infomine.com 